conductivity and the electric conductivity of metals. These researches are described to the Vierteljahrschrift of the Zurich Naturforschende Gesellschaft, 1879, Bd. xxiv, p. 252.

\section{THE INDIA MUSEUM ZOOLOGICAL COLLECTIONS}

THE following letter on this subject has been sent us for publication :-

British Museum, March I7, 1880

MY LORD, - I am directed by the Trustees of the British Musem to acquaint your Lordship that Dr. Giinther, the Keeper of the Deparment of Zoology in this Museum, has reported to them that he has completed the work of selecting from the zoological collections of the India Museum the specimens required for the British Museum, and of distributing the remainder among other institutions.

The accompanying extract from Dr. Giinther's report shows in detail what has been done with those specimens which formed part of the India Museum, and what is proposed with reference to certain other specimens not included in the general transfer to the Trustees. I have, \&c.,

The Right Honcurable the Secretary

EDw. A. Bond of State for India, \&ंc., \&.c.

ZOOLOGICAL COLLECTIONS FROM THE INDIA MUSEUM

Extract from Refort to the Trustees of the British Museum, by Dr. Günther, Keeper of the Department of Zoolosy. Dated March 8, 1880

I. For the British Museum have been selected and retained :-

672 Mammalia (mounted, or in skins, skeletons or shulls).

6,409 Birds.

125 Fishes.

28 Tortoises.

217 Mollusca.

83 Crustacea.

1,813 Insecta.

52 Radiata.

60 Jars and preparation of Economic Animal Products (besides some objects of manufacture transferred to the Ethnographical Department).

The Documents relating to the Zoological collections :-

2. A selection of the remainder was offered in succession to the Indian Museum, Calcutta; the Indian Institute, Oxford; the South Kensington Museum; the Dublin Museum; the Museum of Scarborough ; and the Museum of Maidstone; the three first having been specially mentioned by the India Office as deserving ! recedence of ather institutions.

a. The Agent of the Calcutta Museum selected :-

53 Mammalia and 3 Skulls of Mammals. A series of named shells.

3, 140 Named Insects.

A box of miscellaneous Insects. (The number of bird skins to be sent is not yet determined.)

b. Prof. Monier Williams, on behalf of the Indian Institute Oxford, took the bulk of the remaining specimens, entering at the same time into an engagement to return them to the Trustees in case the project of the Institute were not carried out; he received :-

I 8 Mammalia.

37 Skulls and heads of Mammalia.

49 Horns of Mammalia.

2 Boxes containing various bones.

I Narwhal's tusk.

I Picture of a Flying Fox.

426 Stuffed Birds.

3 Boxes of Bird-slkins.

5 Birds'-nests.

I25 Bottles containing Reptiles and Fishes.

44 Stuffed Reptiles.

2 Models of Snakes.

I Case of Stuffed Snakes.

94 Stuffed Fishes.

4 Models of Fishes.

I Cabinet with Mollusks.

I Box with Shells and Corals.

2 Boxes with Pearl Oysters, \&c.
2 Boxes with Gorgonia.

2 Cases with Crustaceans

5 Cabinets with named Insects.

ro Old Store boxes with various Insects.

2 Echinoderms.

I Neptune's $\mathrm{Cu}_{\text {}}$

I Cabinet with Miscellaneous Specimens; Eggs, Nest, Crustaceans, Shells, \&c.

I Box of Sterna of Hodgson's Birds.

$c$. The South Kensington Museum took the whole of the collection of Economic Animal Products left after the selections for the British Museum and Kew had been made; the latter establishment receiving, by a special arrangement with the India Office, all products of silk and lac.

$d$. The Agent of the Science and Art Museum, Dublin, selected :-

7 Stuffed Mammals.

8 Skulls of Mammals.

I Horn of Cervus duvancelii.

5 Tortoises.

4 Bottles containing Reptiles.

e. The Agent of the Philosophical Society of Scarborough selected :-

Io Mammalia.

f. The Agent of the Museum of Maidstone tock the whole of the remaining spacimens, viz. :-

103 Stuffed Mammals.

1o Skulls,

Before commencing the work of distribution Dr. Günther received intimation from Dr. Birdwood that certain specimens were not included in the general transfer to the Trustees, viz. :-

I. Four small cases of stuffed Birds from Kashgar and an Ibex, belonging to Dr. Bellew, and lent by him to the Indian Museum for exhibition. These specimens would be a valuable acquisition to the British Museum, and therefore Dr. Günther has written to Dr. Bellew, who is at present in Afghanistan, that he would propose to the Trustees to continue the custody of them until instructions shall have been received from him as to their disposal.

2. A case of Wild Dogs, lent for exbibition by Mr. T. Webber, whose address is unknown at present. Dr. Giinther would propose to undertake the temporary custody of this case until it is claimed by the owner.

\section{METEOR SHOWERS 1}

SEVERAL of the meteor streams observed at Bristol within the last two years appear to be of such marked intensity as to merit special description, and the following notes in connection with five of these may possess some interest to observers.
No.
Epoch.
Radiant.
$\circ+0$
Date of Maximum
I. ... July 30-Aug. I $\ldots .32+53 \ldots$ July 31,1878
II. ... July $27-30 \ldots \ldots 341-13 \ldots$ July $27,28,1878-9$
III. ... Angust $21-25 \ldots \ldots 291+60 \ldots$ August $21-23,1879$.
IV. ... October 14-20 $\ldots .31+9 \ldots$ October 15,1879 .
V. ... August $8-1$ I $\ldots . . .444+25 \quad \ldots$ August 8 - I I.

I. At the middle of July, 1877 , a few meteors were traced from a radiant point at $36^{\circ}+47^{\circ}$, and on projecting a large number of meteor tracks registered in foreign catalogues for the period July 25-3I, I found the same shower amply manifested from 25 paths, though the radiant was $5^{\circ}$ higher in declination. A succession of clear nights occurred from July 26 to August 2 in 1878 , and $I$ obtained some lengthy observations. In about twenty-two hours of watching more than 400 shooting stars were seen in the eastern sky, chiefly amongst the constellations of Perseus, Cassiopeia, and Andromeda. I saw many swift meteors leaving short streaks and otherwise exhibiting much uniformity in their appearances and directions. The radiant point was not reconcilable with that of the well-known annual shower of Perseids. It was sharply defined about $3^{\circ} \mathrm{S}$. of the group $\chi$ Persei, and the maximum of the shower was witnessed on July $3 \mathrm{I}$, when $2 \mathbf{I}$ meteors were noted diverging from the point described. In all I saw 63 meteors conforming to this stream; they were short and quick, always with streaks of $3^{\circ}$ or $4^{\circ}$ in the latter portion of their flights. I looked for the shower again in 1879, and

I Extract from a paper in the Monthly Notices of the Royal Astronomical Society, vol. xl., No. 3 (January, 1880 ). 
recovered it both on July 28 and 29 . It appears to be identical with a radiant given by Schmidt at $31^{\circ}+55^{\circ}$, August 3-12. The diagram shows the observed paths of $86 t^{\text {s }}$ (in the region of the radiant point) recorded at Bristol in the years $1877^{-8}$, and includes some tracks in the catalogues of foreign observers.

II. Contemporary with these, $\chi$ Perseids, or Perseids II, my observations in July, 1878, led me to recognise a large number of slow meteors with long paths (averaging $17^{\circ}$ ) and occasionally leaving faint trails of sparks, ascending amongst the stars of Pegasus, Andromeda, \&c., which, by their parallelism of motion, obviously proceeded from a common radiant point south of Pegasus. I watched them narrowly, and determined the position with fair precision as near $\delta$ Aquarii. The best display of this fine shower was on July $\mathbf{2 7}$, when 22 of its meteors were recorded, and in the $\frac{3}{4} \mathrm{~h}$. preceding midnight on July 30 , eight of

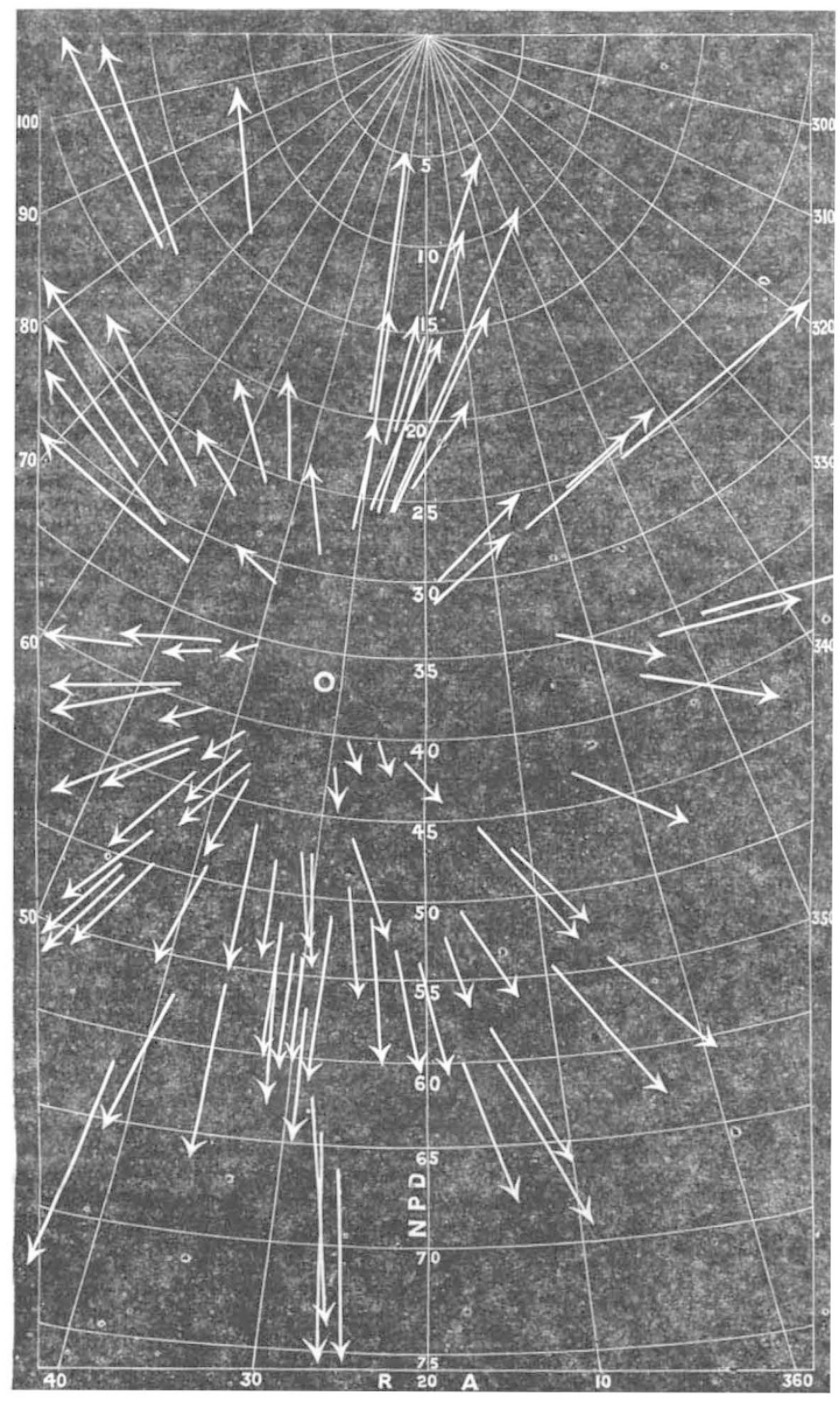

Fig. I. - Shower of $\chi$ Perseids, or Perseids II, near the radiant point $32^{\circ}+53^{\circ}$, max. July 28 -August $x$.

these Aquariads were visible, though the radiant was close to the horizon; but on the following night the shower appeared to have become extinct. In 1879 , July 28 , it reappeared, yiving very long gradual meteors similar to those seen the year before. The continuation of this radiant in August is rendered extremely probable by my observations in 1877 , when I detected a good centre at $342^{\circ}-12^{\circ}$ from 12 meteors, August $3-16$, and by a bright stationary meteor, also recorded at Bristol, on August 9,
1879 , at $342^{\circ}-16^{\circ}$. Major Tupman had obtained the best previous observations of this shower. On July 27,1870 , and several ensuing nights, he saw many meteors from an accurate radiant at $340^{\circ}-$ $14^{\circ}$, and the position and epoch of the shower, as he determined it, agree perfectly with its apparition in $1878-79$ recorded at Bristol. Prof. Herschel had also, as early as July 28, 1865, traced a few of its meteors. There are iater showers (of very slow meteors) from the same region of Aquarias. The diagram 
shows $4 \mathrm{I}$ tracks registered at the end of July, chiefly in 1878 , at Bristol.

III. Beginning to observe at about 9h. $30 \mathrm{~m}$. on August 2I, I879, I immediately found a very active shower of slow, trained meteors proceeding from a point in Draco. I noted 9 of them in the $\frac{3}{4} \mathrm{~h}$. before roh. $15 \mathrm{~m}$., though afterwards the display became less
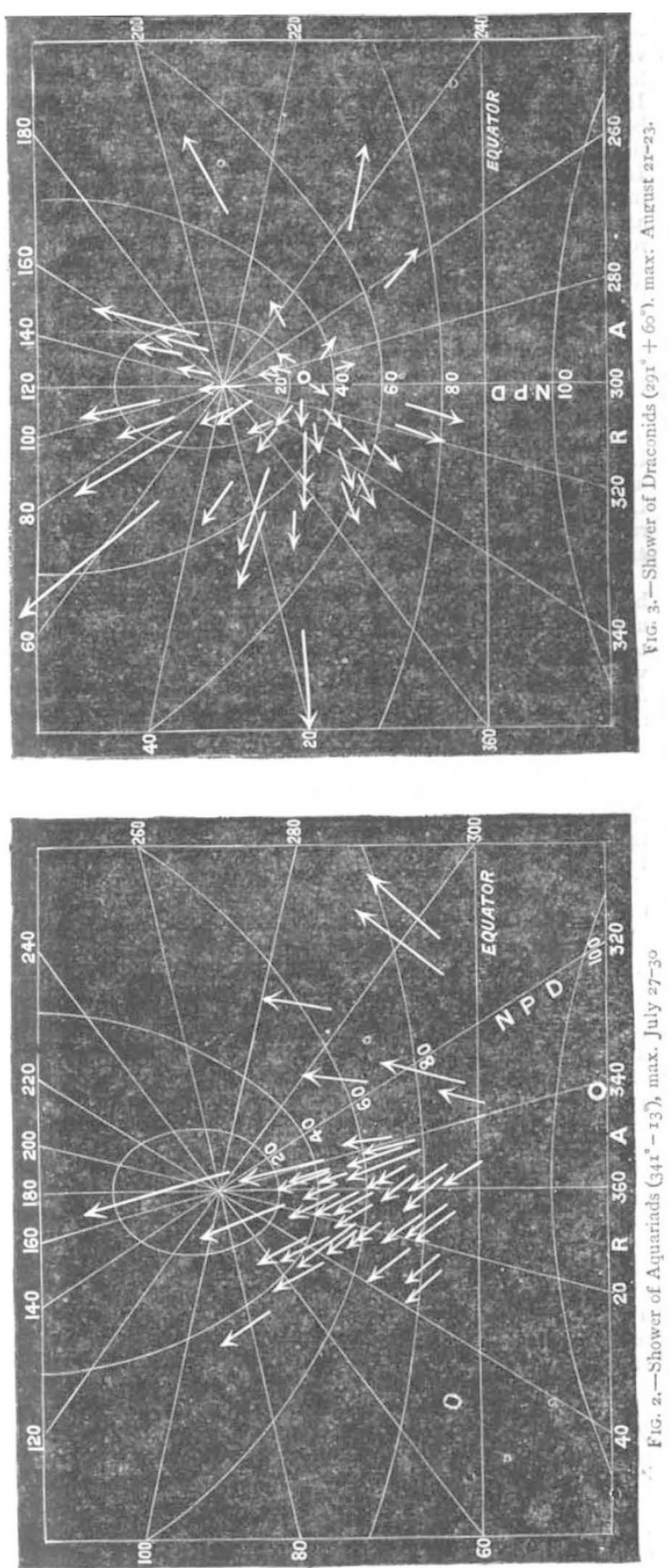

decided, and of the 68 meteors which I counted up to $13 \mathrm{~h}$. $30 \mathrm{~m}$. (when clouds overspread the sky) $2 \mathrm{I}$ belonged to this system.

The two ensuing nights were clear, and I saw 143 shooting stars, including $3 \mathrm{I}$ additional paths conforming to the special shower in Draco, the exact position of which I determined at $291^{\circ}+60^{\circ}$ (near o Draconis). The total number directed from this stream
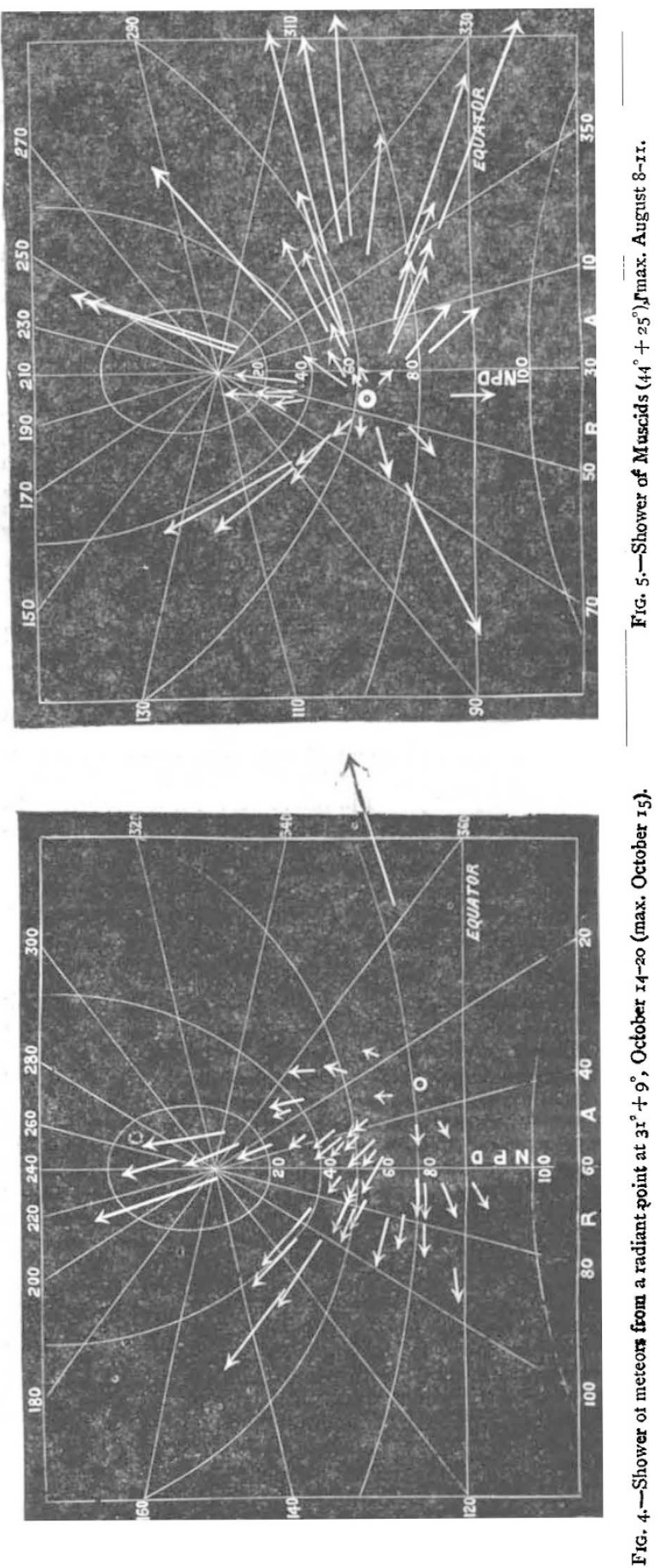

(No. 78) of Greg's "Catalogue of Meteor Sbowers" (1876), in which the position is averaged at $282^{\circ}+60^{\circ}$ and the whole duration extends from June 28 to August 25 (?) from 12 observations. There are other conspicuous showers directed from the same region in Draco at many other periods of the year. The diagram 
gives $4^{I}$ paths, nearly all of which were traced on August 2I-23, I879.

IV. On October I 5,1879 , the sky was watched for eleven hours (6h. $30 \mathrm{~m}$. to $17 \mathrm{~h}$. $30 \mathrm{om}$.), and of the 127 shooting-stars seen during that lengthy observation, 21 were slow meteors from a radiant point at $3 \mathbf{1}^{\circ}+9^{\circ}$, but the position was not well defined. I had seen several meteors from the same region on the previous night, and on the 2oth, when the sky was again favourable, I recorded Io others, making 37 in all from this shower in the south of Aries. They were generally faint, with rather short paths, and decidedly slow. The same radiant was seen by Major Tupman in 1869 , October 13 , at $28^{\circ}+10^{\circ}$, and $\mathrm{Mr}$. Corder has distinguished a series of Octoper positions in Aries and Pisces. The diagram (IV.) includes 42 paths observed by $m e$ in the years $1876-79$, but chiefly in 1879 .

V. At about the middle of August, 1877 , a few rapid meteors were traced from a radiant in Musca at $40^{\circ}+28^{\circ}$, and in the following year, while noting the progress of the Perseids, I recorded several fine meteors, leaving streaks, and with paths averaging $40^{\circ}$. The radiant was evidently on the horizon, and the directions of the meteors, which in several instances were very exactly observed and mapped, indicated the point $44^{\circ}+25^{\circ}$ as the diverging focus of the shower. With the object of further investigating it, I examined the observations made at the epoch of the Perseids, by the Italians in 1872 and by Zezioli in I867-70, and found many meteors conforming to this shower of Muscids, which had already been detected by Weiss in 1869, August I I, $46 \frac{1}{2}^{\circ}+23 \frac{1}{2}^{\circ}$, and August 12, $41 \frac{1}{2}^{\circ}+24^{\circ}$. In this region, between Musca and the east extremity of Aries, there are many successive showers during the four months from August to November. Early in August, when the first display is perceptible, the meteors are very swift, with unusually long paths, and seldom without streaks ; but in October and November the motions are generally slow, and the phosphorescent streaks, forming so persistent a feature of the earlier displays, have given way to occasional trains of ashy sparks. The August shower above referred to merits description, as supplying some fine long meteors in the mornings of August. Thirty-eight paths are shown in the diagram, several of which are notable on accor $n$ of inordinate length.

The several showers here mentioned, being apparently of little less importance than the Orionids, Geminids, Taurids, \&c., will no doubt be frequently seen in future years; and it seems desirable to select them trom the mass of feeble systems now ascertained, as affording displays of more than ordinary richness.

W. F. DENNING

\section{CHEMICAL SOCIETY-ANNIVERSARY $M E E T I N G$}

$W^{E}$ take the following extract from the address, at the Anniversary Meeting, of the Chemical Society on March 30, by the president, Dr. De la Rue :-

Although since my last term of office I have not been precisely in a sleepy hollow, like that described by Washington Irving, nevertheless my thoughts have been mainly absorbed by other branches of science, and I found myself, on returning to this chair, very much in the same perplexity as Rip Van Winkle when he awoke in the Kaatskill Mountains after his long sleep.

So rapid has been the progress of our science, that much of the aspect of chemical thought has altered in the interval; old and once familiar bodies have not only changed their nomenclature, but new and unfamiliar individuals and families have crowded into the greatly extended domain of chemistry. The very elements which are looked upon as most stable are now considered to be in a critical position, and liable at any moment to dissociation; for it is only a few months ago that the minds of chemists were disturbed by the announcement that spectroscopic evidence afforded by the sun and stars tended to show that the so-called elements were in reality compound bodies. Even if we reserve our judgment on this point, we can no longer assert that the light emitted from the so-called elements, when incandescent or vaporised, is characterised by certain definite wavelengths. Moreover, we learn that a well-known German chemist, Professor V. Meyer, has actually succeeded in dissociating the halogens, chlorine, bromine, and iodine. The results which he and his coadjutors have obtained appear to leave little doubt that such is actually the case, and we must await the outcome of their continued labours with intense interest.
As regards the spectrum itself, we can no longer attribute certain specific functions and properties to different parts of it; for Captain Abney has shown that every part of the spectrum aets actinically and he even goes so far as to hold out a prospect of Becquerel s beautifut discovery being further extended, so as to produce permanent photographs of the spectrum in its natural colours. In his l3akerian lecture to the Royal Society, Captain Abney has made known his method of preparing a form of silver bromide, sensitive not only to the ultra-violet and the whole visible spectrum, but also to the infra-red rays, and has presented to that Society his magnificent map of the infra-red spectrum. It is difficult to overrate the value of this discovery, and it may be expected that important results will accrue from the investiga. tion of the infra-red absorption spectra of various substances. Indeed, Captain Abney has already informed me of his progress in this direction. The importance of photography, not only as aftording a means of investigation, but as a method of permanently recording observations which may be dealt with at leisure, thus affording the means of accurate measurement, in such hands as those of Dewar, Liveing, and Abney, cannot be too highly prized.

A problem which had long baffled all efforts, the artificial production of the diamond, is said to have been solved. $\mathrm{Mr}$. Hannay's communication on the subject is so vague, however, that it is impossible to pronounce any opinion on it. The observations on the solubility of solids in gases, which led $\mathrm{Mr}$. Hannay to attempt to crystallise carbon, and which are described in a recent communication to the Royal Society by Messrs. Hannay and Hogarth, are of great interest, and most important results will doubtless be obtained by an extension of these experiments.

The necessity for further information on the subject of the behaviour of various substances, and especially of mixtures under great pressure, is well shown by the recent remarkable observations of Cailletet, that on compressing a mixture of five volumes of carbon dioxide and one volume of air, the former at first liquefies; but that as the pressure is increased to 150-200 atmospheres, the meniscus of the liquid carbon dioxide becomes plane, and is gradually effaced, until finally the liquid wholly disappears, apparently dissolving in the gas.

Mr. Ansdell s papers on the "Physical Constants of Liquid Acetylene and Liquid Hydrogen Chloride," as determined with the aid of the Cailletet apparatus in the laboratory of the Royal Institution, are valuable contributions to our knowledge of chemical physics, and appear to furnish the interesting result, that the volume of the fluid and gas are equal at the critical point in the case of the latter substance.

Another investigation in chemical physics of great interest is that recently published by Bribl, who has considerably extended the observations of Gladstone, Landolt, and others, on the refractive indices of carbon-compounds. The introduction of a new method of calculating the results by which the influence of dispersion is eliminated, has led him to the discovery of an apparently very simple relation between chemical constitution and refractive power.

The extraordinary diligence of chemists who apply themselves to the investigation of carbon-compounds has also reaped a rich harvest of results. It would be impossible for me to consider the progress of this branch of chemists y in detail, but I cannot help noticing how rapidly the more complex bodies, such as the alkaloids and the carbo-hydrates, are being forced to yield up the secret of their constitution, which has so long been withheld. The synthesis of Isatin by Claisen and Shadwell, and the researches of Baeyer in the indigo-group, must, it would seem, ere long, result in the discovery of a method for the artificial manufacture of this colouring matter.

Ladenburg's success in preparing the alkaloid atropine from Tropine and Tropic acid, the two substances which it furnishes when decomposed by hydration, is no doubt the first step towards the synthesis of an alkaloid. Great advances have been made in unravelling the constitution of the bases of the Pyridine and Picoline series, and much light has been thrown thereby on the constitution of nicotine and the Cinchona alkaloids. Moreover, important additions have been made to our knowledge of starch. It is remarkable, also, that a number of new facts have been brought to light tending to prove that the symbolic system at present employed to represent the constitution of carbon. compounds is insufficient.

The year has not passed by without announcements of new members of the family of Elements. One of the most inter- 